\title{
PLASMA DEPOSITION OF ORGANIC THIN FILMS FOR SURFACE MODIFICATION
}

\author{
BUDDY D. RATNER \\ Center for Bioengineering and Department of Chemical Engineering \\ University of Washington, Seattle, Washington 98195 USA
}

\begin{abstract}
Plasma deposition of organic thin films represents a flexible strategy for tuning the surface chemistry of materials for specific applications. The advantages of such films are summarized, surface characterization is discussed and specific applications for biology and medicine are reviewed.
\end{abstract}

\section{Introduction}

Many fields of technology including microelectronics, adhesion science, biomaterials and catalysis make use of surface modification to engineer surface properties. The goal of surface modification is to take an existing material or manufactured device and, without altering its mechanical properties or manufacturability, improve its surface properties (e.g., corrosion resistance, printability, electrical properties, reactivity, biointeractions or bondability).

Many ingenious and useful techniques have evolved for modifying just the surface structure, while keeping the bulk structure unchanged [1-4]. In this article, I propose that the deposition of organic thin films from low temperature, non-equilibrium, ionized gas plasmas is among the most versatile and practical of these methods $[5,6]$.

Plasmas can be used in a few general ways to treat a surface: (1) etch, oxidize, chemically react the surface, (2) activate reactive groups on a surface permitting grafting or attachment of other species [7], and (3) deposit overlayer films on the surface. These approaches are illustrated schematically in Figure 1. The examples in this brief review will deal exclusively with plasmas that deposit thin films. 


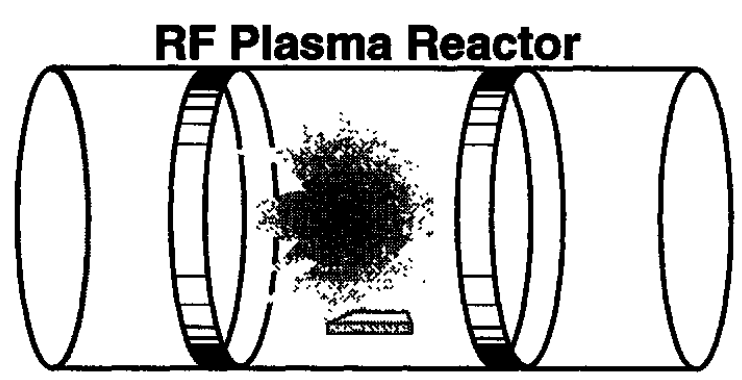

Three Classes of Surface Modifications

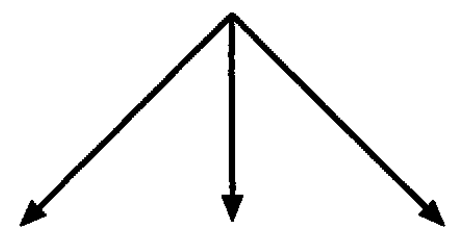

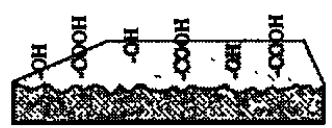

Etch and introduce new functional groups

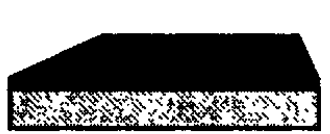

Plasma

Deposition
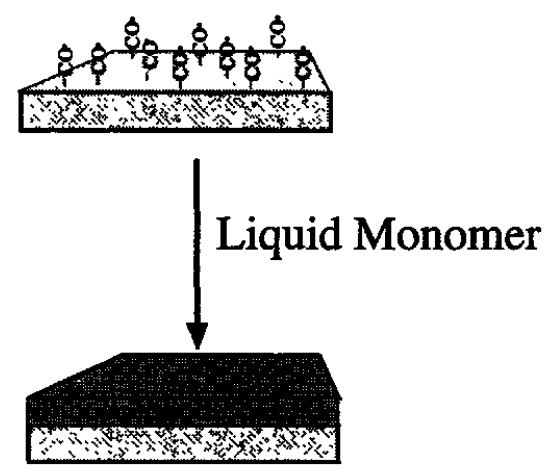

Graft surface modification

Figure 1. Plasmas can be used to etch polymers, deposit thin films or create functional groups which can be used for further surface grafting.

The advantages of plasma deposition of organic thin films are summed up in the following points:

1. A wide range of surface chemistries can be achieved. Hundreds of organic compounds that cannot be polymerized by convention polymer mechanisms are readily deposited as polymeric thin films in a plasma environment. The wide range of volatile organic compounds that are available for deposition are an advantage of organic plasmas over inorganic plasmas, where chemical variations are limited.

2. Plasma processes can be used to treat whole, manufactured devices. The coatings are conformal, can penetrate small spaces, and do not necessarily require line of sight treatment. However, there are limitations associated with the device geometry and its vacuum 
compatibility.

3. The deposition chemistry is generally independent of the substrate. Thus, a desired surface chemistry can be applied to polymers, metals, ceramics, carbons and glasses. The interfacial adhesion of these plasma deposits to the substrate must be understood for a durable deposition. This can be achieved through an appreciation of surface contaminant layers, weak interfacial layers and surface mobility.

4. Plasma deposition is a dry process performed in a low pressure environment. Manufacturability is enhanced compared to wet surface modification processes because of reduced contamination and environmental concerns.

5. The processing is rapid with surface modification often effected in seconds. Continuous processing with roll-to-roll (air-vacuum-air) reactors is straightforward and is viewed as being extremely desirable for sheet, wire, and tubing geometries.

6. The coatings are pin-hole free and conformal suggesting applications for electrode insulation, diffusion barriers and corrosion protection.

7. Many of these coatings are good permeation barriers and can protect a device from water, ions and other aggressive agents.

8. The monomer costs are negligible since the reactions occur at low pressures and the films are thin.

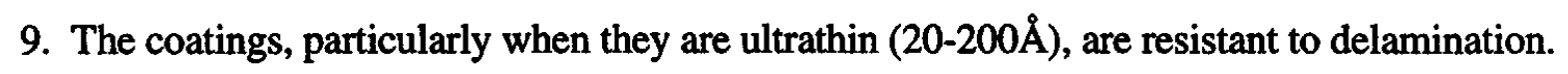

10. There is much art and precedent for plasma depositions, since the microelectronics industry uses this technology.

\section{A Brief Description of Methodology: Synthesis and Characterization}

Plasma deposition methodology has often been discussed [8,9]. Plasmas can be readily generated using radio-frequency (RF), audio frequency, microwave or direct current energy sources. A simple RF plasma reactor is illustrated schematically in Figure 2 . The principal components of a 
plasma reactor are a gas introduction/mixing system with mass flow controllers, a reaction chamber constructed of relatively inert materials (e.g., glass, quartz, or stainless steel), a method to couple energy into the gas in the reactor (e.g., an inductively or capacitively coupled RF energy), and a pumping system, including contamination traps, throttle valve (to control pumping rate), and vacuum gauges (typically capacitance manometer gauges or thermocouple gauges are used).

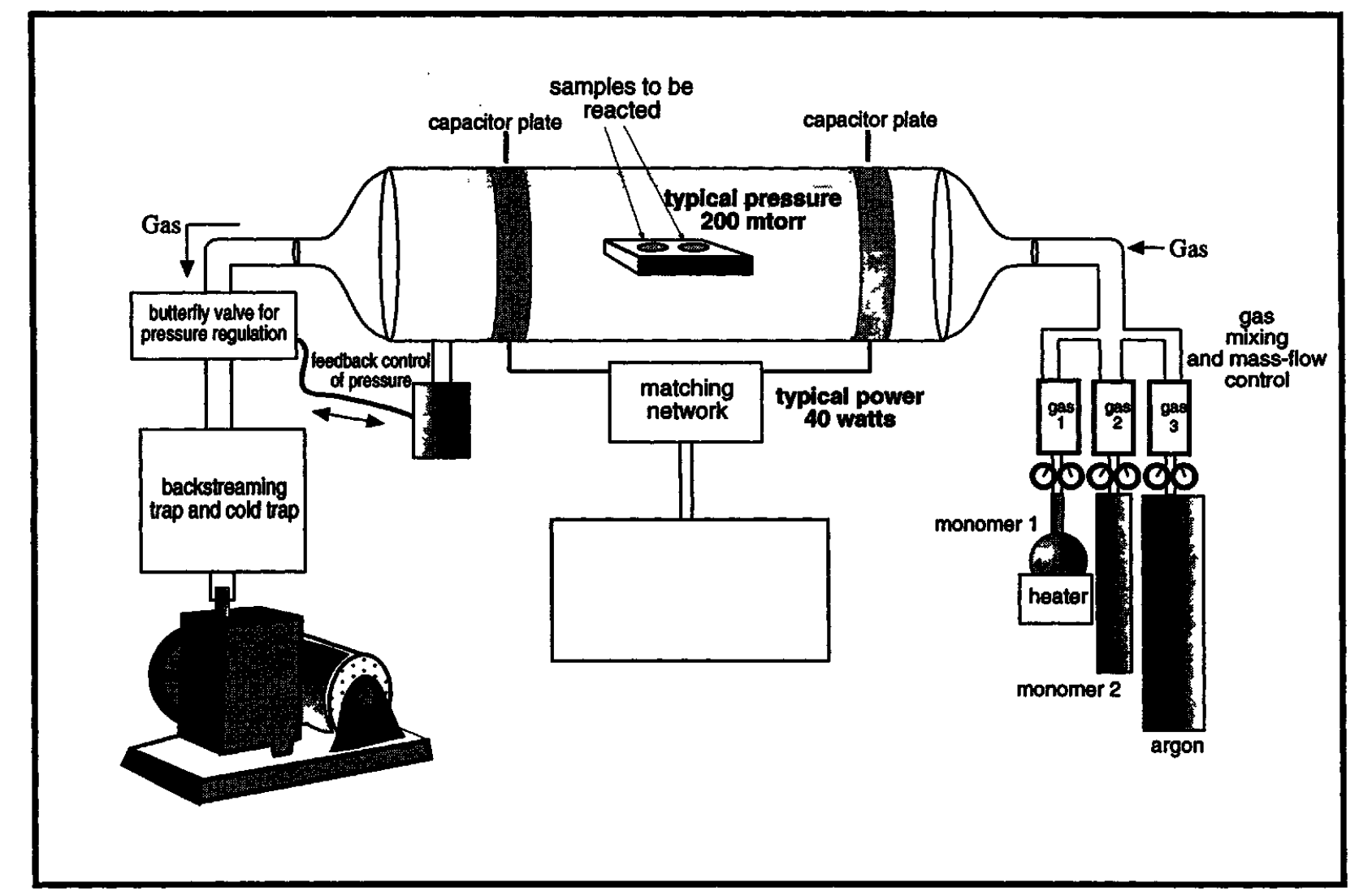

Figure 2. A schematic diagram of a capacitively coupled RF-plasma reactor.

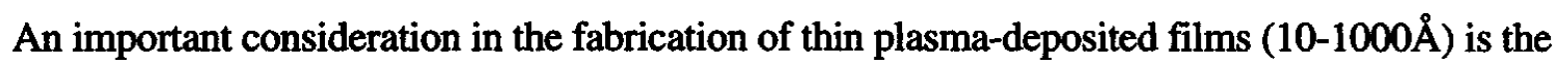
analysis of their nature, including chemistry, macromolecular morphology, thickness, wettability and texture. The tools of contemporary surface analysis are particularly useful for such analysis. Electron spectroscopy for chemical analysis (ESCA), static secondary ion mass spectrometry (SIMS), contact angle methods, atomic force microscopy (AFM), ellipsometry and infrared methods, have proved of special utility. Figure 3 presents the ESCA spectra of a polystyrene surface before and after treatment with a perfluoropropane, or an acetone, plasma. Surface analysis methods have often been reviewed [10-15]. 


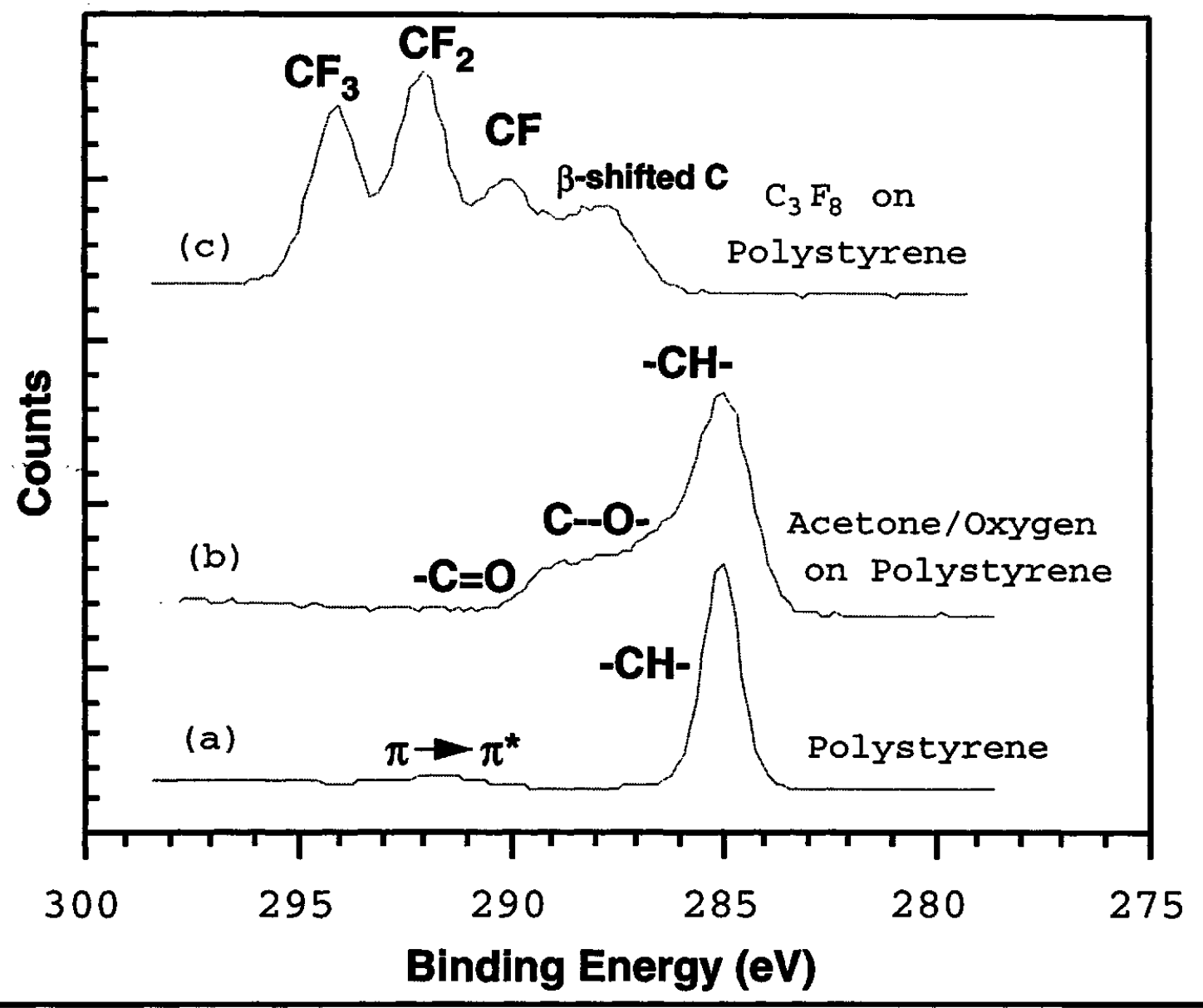

Figure 3. C1s ESCA spectra of a polystyrene surface (a), treated with an acetone/oxygen plasma (b), or a perfluoropropane plasma (c).

Organic plasma depositions should be thin for the best resistance to delamination and the shortest practical processing time. Layer thickness is often measured in situ with quartz crystal microbalances or by ellipsometry. The mass of material deposited on the surface can be estimated from an ESCA measurement of overlayer thickness [16,17] and an estimate of film density. Plasma deposits are typically on the order of $10^{-7} \mathrm{~g} / \mathrm{cm}^{2}$ to $10^{-5} \mathrm{~g} / \mathrm{cm}^{2}$. Many conventional chemical analytical methods do not have the sensitivity or surface localization to analyze such small amounts of polymer, hence the need for special methods.

Some methods traditionally associated with the analysis of the bulk of materials have been used with good results for plasma deposition analysis. These including nuclear magnetic resonance (NMR)[18], and electron spin resonance (ESR) [19,20].

There are a few special surface analysis issues that must be dealt with in plasma surface 
modification. These include changing or drifting chemistries at the deposition surface [21], surface reversal or migration of coating material into the bulk [22], delamination resistance, the analysis of crosslink structure [23], and dealing with the chemical complexity (multi-fuctionality) of plasma films $[24,25]$. The literature references offered illustrate that some progress has been made in addressing each of these issues.

\section{Surface Structures: Retention or Loss of Chemical Structure}

The energetic species in the plasma environment have sufficient energy to break any organic bond. Consequently, plasma-deposited films generally have a scrambled chemical structure that has little resemblance to the starting monomer. This film may have useful properties, but its chemistry is illdefined and multifunctional. To develop plasma-deposited films with a surface structure resembling the starting monomer, we condense the monomer onto a cold stage at the same time that plasma energy density is reduced. By using this technology, poly(ethylene oxide)-like films [26], poly(2-hydroxyethyl methacrylate) deposits [27], novel fluoropolymer deposits [27] and polystyrene coatings [28] can be synthesized. Figure 4 shows the ESCA spectra of a poly(2hydroxyethyl methacrylate) film that was plasma-deposited under high reactor power and ambient temperature conditions, and another film that was plasma-deposited under low deposition power and low substrate temperatures. The plasma deposition chemistry can be controlled to a considerable extent by manipulation of substrate temperature and deposition power. However, it can also be controlled by pulsing the plasma power [29] or by depositing downstream from the glow in the plasma reactor [30].

\section{Plasma Depositions in Biology and Medicine}

Our research group at the University of Washington is especially involved in the application of plasmas to problems in biology and medicine. Plasmas are now widely used in the biomedical community to surface treat polystyrene or poly(ethylene terephthalate) for cell growth or for immunoassays. Plasmas represent a unique and implementable method to alter the surface characteristics of devices and materials used in medicine and biology [8,31]. The rationale for altering biomaterial surfaces will now be presented. 


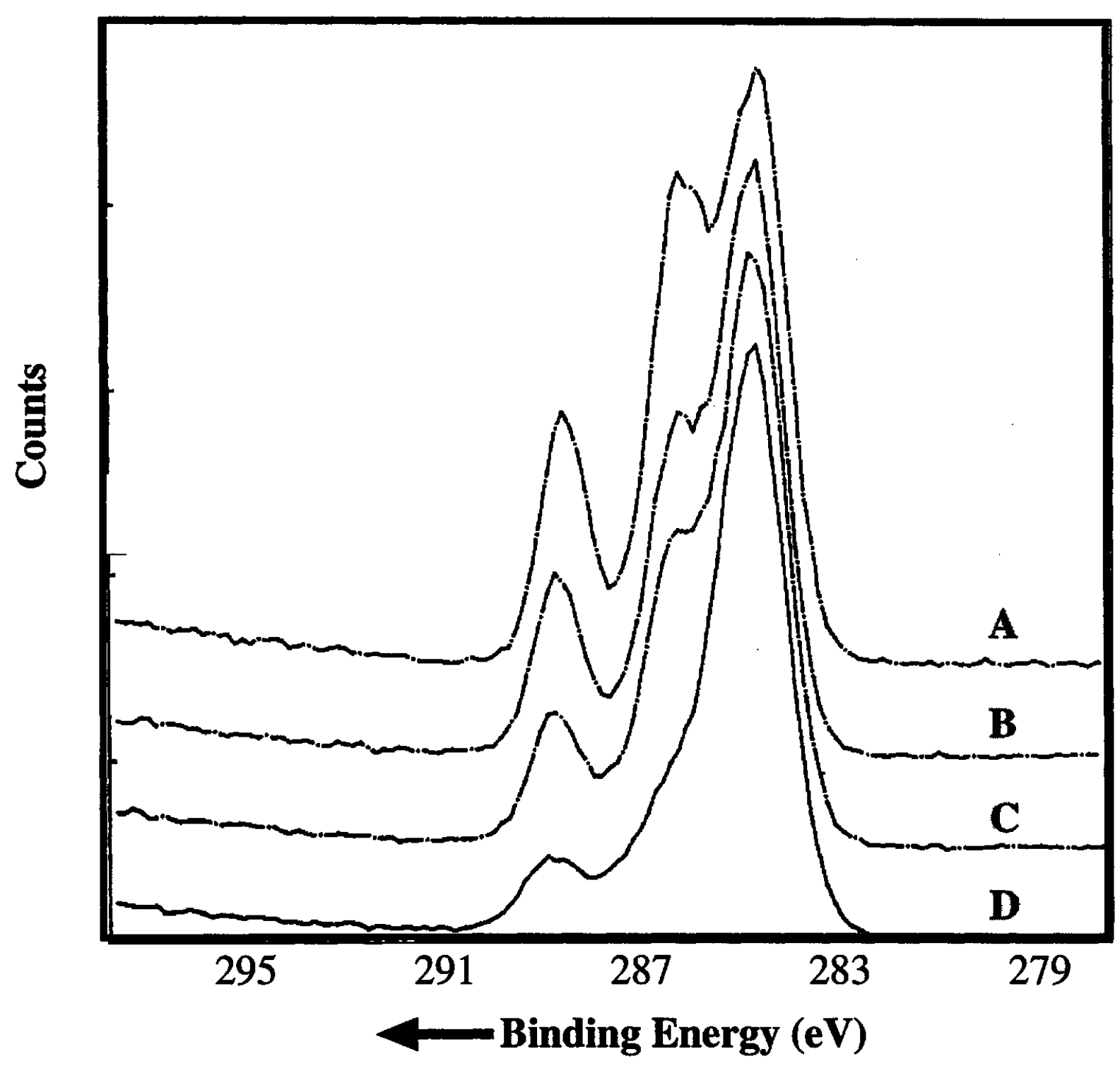

Figure 4. HEMA monomer deposited at various plasma powers and substrate temperatures (see reference 27 for further details).

Biological systems (e.g., proteins, cells) are sensitive to the nature (structure and composition) of a surface. Many papers demonstrating such surface structure-reactivity correlations are cited in references 32 and 33 . If the biological response obtained from a biomedical device or material (e.g. the soft tissue biocompatibility, the blood compatibility, the enzymatic activity, etc.) is not satisfactory, we might alter only the surface zone of a device or material using a plasma, leaving its mechanical and performance qualities intact, but yielding a new biological reactivity. In addition, plasma treatment provides a powerful set of tools to alter performance characteristics of devices and materials. Examples include changes in the lubricity, permeability, hardness, electrical 
conductivity and bondability.

Thus, plasma deposits show special biointeractions, are durable, are inexpensive and are manufacturable. This forms the basis for our interest in this class of materials. A general review article has been written that further elaborates our interest in plasma depositions for biomedical applications [8]. Some specific examples follow.

\section{Plasma-deposited Coatings for use in Contact With the Blood Stream}

Plasma fluoropolymer coatings (similar in chemistry to that shown in Figure 3c) that exhibit an extremely low reactivity to blood platelets have been developed [34,35]. The low platelet reactivity is suggested by the data in Figure 5 (vascular prosthesis patency) and by results with Doppler flow studies, ${ }^{111}$ In gamma imaging of platelets in a baboon shunt, and laser light scattering emboli detection.

\section{Cell Growth on Plasma Deposited Films}

Films prepared by plasma deposition from some volatile carbon and oxygen containing precursors have been shown to produce stable surfaces that exhibit excellent cell growth [36,37]. The ESCA spectrum shown in Figure $3 \mathrm{~b}$ is typical of the surface chemistry of this class of polymers. To date we have evaluated growth of 3T3 fibroblasts, bovine aortic endothelium, human umbilical endothelium, human adult endothelium and epithelial cells, and have found good growth, for certain surface compositions, with all of these cell lines. Since the surface modifications permitting good cell growth are depositions, they can be applied to any substrate, unlike the plasma-oxidized polystyrene (tissue culture polystyrene or TCPS) used in conventional cell culture. The structural characteristics that promote cell growth in this type of deposit have not yet been fully defined. However, certain facts are known. An increase in cell growth ability with increasing surface oxygen content, as measured by ESCA, is often observed. However, oxygen content does not always correlate well with cell growth. For example, poly(ethylene terephthalate) and poly(2hydroxyethyl methacrylate), polymers with relatively high oxygen contents, are poor cell growth substrates. Surface carbonyl content, as measured with ESCA using a hydrazine derivatization reaction, correlated well with bovine aortic endothelial cell growth [38]. However, we have demonstrated that carbonyl groups, while perhaps necessary for cell growth, are not sufficient -- a purely carbonyl surface will not support cell growth. In the same study we found that the hydroxyl content or carboxyl content of the polymers did not correlate with cell growth. Also, it has been observed that the the more tightly proteins are bound to the surface (as measured by resistance to 
sodium dodecyl sulfate elution), the better the plasma deposited surfaces grow cells [39]. This observation leads us to believe that a plasma deposited film containing carbonyl groups as well as other, as yet undetermined, functionalities, will tightly bind proteins, and this will, in turn provide a good cell growth substrate. Most recently, we have related the multifunctional nature of plasma deposited films to their cell growth characteristics using multivariate statistics [40].

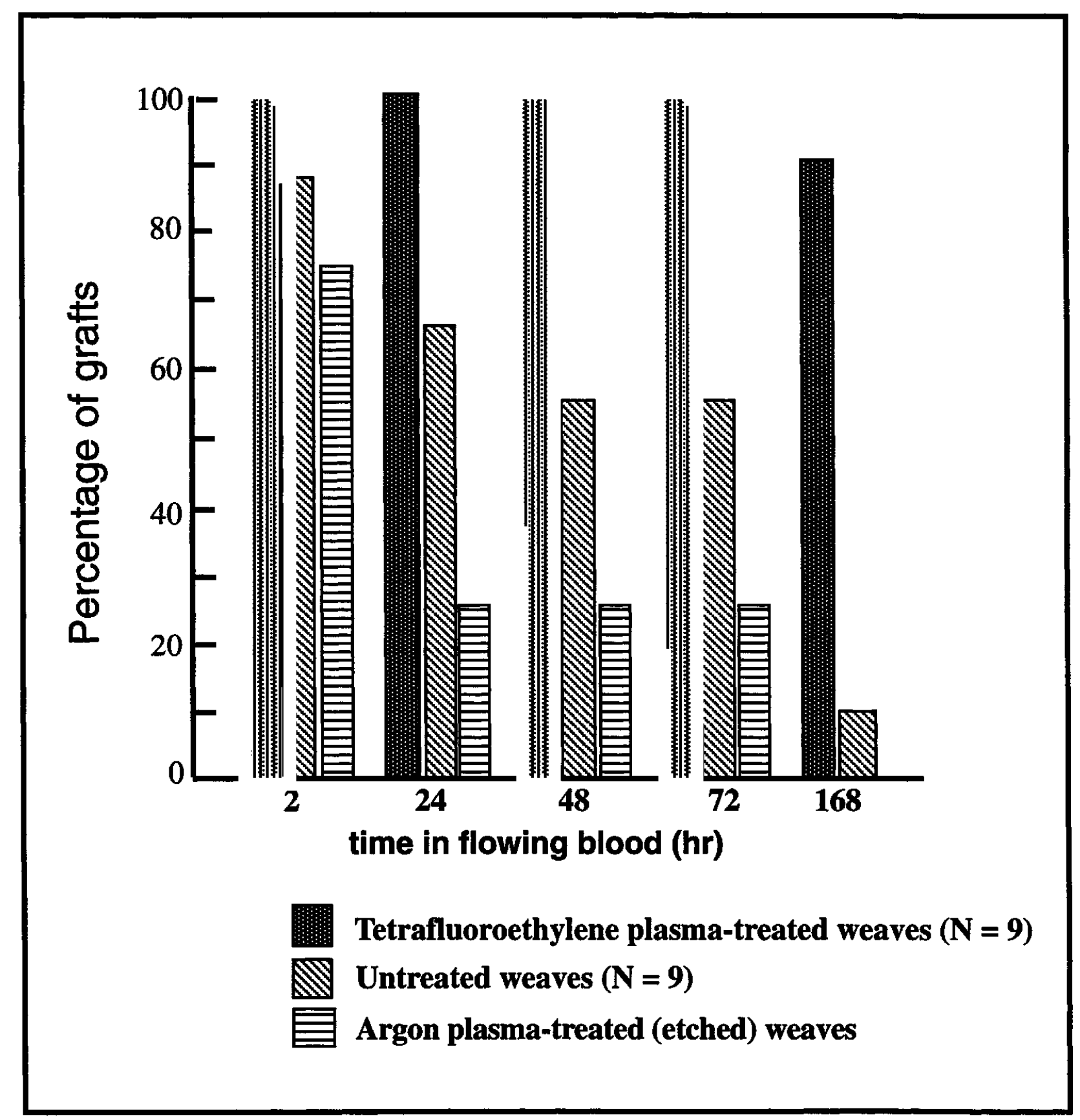

Figure 5. Vascular prosthesis patency, untreated, after tetrafluoroethylene deposition and after argon etching (from reference 35). 
Non-fouling surfaces

Poly(ethylene oxide)-like plasma deposited films can be prepared from low molecular weight precursors such as tetraethylene glycol dimethyl ether (TEGDME) [26]. TEGDME, although of low volatility, can be heated to raise the vapor pressure sufficiently so that a plasma can be ignited. The monomer will condense on ambient temperature objects in the reactor and therefore can be used where simultaneous condensation and plasma deposition is desired. Because of TEGDME condensation, the walls of the plasma reactor must be heated during deposition. TEGDME films, deposited upon appropriate mild conditions, show extremely low protein adsorption [26]. This has been observed for single proteins in solution and for adsorption of proteins from plasma. Also, these TEGDME plasma-deposited surfaces will not support the attachment of human blood platelets, or the attachment and growth of bovine aortic endothelial cells [26]. Static SIMS studies reveal that the longest poly(ethylene glycol) (PEG) chains in these films may be only three repeat units. Other investigators report that much longer PEG chains are necessary for low protein adsorptivity $[41,42]$. The high density of chains on the surface achievable by grafting from the vapor phase may lead to the non-fouling characteristics for these surfaces.

\section{Intraocular lenses and Contact Lenses Modified by Plasmas}

Surface modification of intraocular lenses (IOLs) and contact lenses is a subject of considerable interest to address performance problems with both these devices. Concerns over the magnitude and duration of the foreign body reaction to implanted IOLs have recently been expressed. Also, a lens surface that is non-adhesive to the corneal endothelium is desirable. A plasma fluoropolymer treatment with perfluoropropane gas produces an IOL surface with reduced adhesiveness for corneal endothelium [43]. In the same experiments, hydrogel plasma films were also seen to minimize the adhesion of the corneal endothelium. These lenses are presently under investigation to see if other biocompatibility advantages can be realized from these coatings.

Contact lenses often suffer from excess protein accumulation reducing visual acuity and lens comfort. Since the TEGDME coating is resistant to protein pickup, the potential of this coating to suppress protein films buildup is under investigation.

\section{Conclusions}

Plasma deposition of organic thin films offers a powerful set of tools for surface modification. The potential of plasma-deposited polymeric coatings to improve the performance of biomedical 


\section{J. Photopolym. Sci. Technol., Vol.8, No.3, 1995}

materials and devices is suggested by the studies reviewed here. However, before the widespread application of these films in biology and medicine is seen, a number of problems should be addressed. The primary problems are associated with reproducibility in manufacturability, quality control, plasma film stability and durability. Abrasion and deformation of deposits on plastic or elastomeric substrates can lead to film loss or cracking. The potential to deposit elastomeric films from an RF-plasma environment is being explored in our laboratory. However, since these films are always ultrathin and relatively soft (i.e., polymeric), they will be subject to damage by abrasion.

Some concern has been expressed about the stability of the surface chemistry with time of exposure to air. Some films are seen to steady accumulate surface oxygen with time after preparation. Other films show stable surface chemistries for months after preparation [38]. Such chemically stable surfaces are, of course, more desirable for biomedical applications.

A significant impediment to the wider application of plasma deposition in biomaterials science are the problems associated with reproducibility and reactor specificity. If a reactor configuration is altered, reaction parameters have to be redeveloped, often a tedious process. By monitoring the gas phase species in the plasma, the optical emission from the plasma and the surface chemistry during deposition, pattern recognition methods might be used to adjust the plasma parameters to a state that will produce surfaces (as assessed by ESCA and SIMS) of desired characteristics. There are many excellent studies dealing with monitoring of gas phase species in plasma reactors, and relating these species to the nature of the deposited film $[44,45]$. Surface parameters also have been monitored in situ by infrared methods to control plasma film surface chemistry [46].

Finally, the structure of plasma deposited films is extremely complex and is characterized by a broad distribution of chemical functional groups and chain crosslinks. Before we truly understand how plasma deposited films perform in contact with living systems, we must understand what their structure is. Although much progress has been made in the area, particularly using ESCA and SIMS [47,48], much remains to learned. Newer techniques such as those using synchrotron radiation (EXAFS, NEXAFS, $x$-ray absorption), scanning probe microscopies (STM, AFM), advanced SIMS methods (time-of-flight, surface analysis by laser ionization, tandem SIMS) and high resolution electron energy loss spectroscopy (HREELS) will advance the understanding of plasma thin films. Because of the complexity of these coatings, the surface characterization of plasma deposited films will be a fertile subject for investigation for many years to come.

As a research area, plasma depositions involving organic and polymeric species have evolved 
independently from plasmas used widely in the microelectronics field. The organic plasma field has its own researchers, methods, problems and special applications. To provide a focus for this special class of surface modifications, a new journal has been formed, Plasmas and Polymers, edited by Professor R. d'Agostino and this author.

\section{Acknowledgement}

Support from NIH grant RR01296 was received for many of the studies presented in this review. Other grants that have funded programs described here are HL19419 and HL22163. Support from the Alcon Corporation was received for intraocular lens studies.

\section{References:}

(1) J.C. Soutif and J.C. Brosse, Reactive Polymers, 12, (1990) 3-29.

(2) B.D. Ratner, Biosens. Bioelect., (1995), in press.

(3) J.E.E. Baglin, NATO ASI Ser. - Appl. Sci., 144, (1988) 369-376.

(4) F. Garbassi, M. Morra and E. Occhiello, "Polymer Surfaces: From Physics to Technology", John Wiley and Sons, Chichester, UK, (1994).

(5) R. d'Agostino, "Plasma Deposition, Treatment and Etching of Polymers," Academic Press, San Diego, 1990.

(6) H. Yasuda, "Plasma Polymerization," Academic Press, Inc., New York, 1985.

(7) S. Cartier, T.A. Horbett, and B.D. Ratner, J. Membr. Sci., (1995), in press

(8) B.D. Ratner, A. Chilkoti, and G.P. Lopez, in Plasma Deposition, Treatment and Etching of Polymers, R. d'Agostino, Ed., Academic Press, San Diego, (1990), pp. 463-516.

(9) H.V. Boenig, "Fundamentals of Plasma Chemistry and Technology," Technomic Publishing, Lancaster, PA, (1988).

(10) B.D. Ratner, in Concise Encyclopedia of Medical and Dental Materials, D.F. Williams, Ed., Pergamon Press, Oxford, (1990), pp. 337-346.

(11) B.D. Ratner, "Surface Characterization of Biomaterials," Elsevier Press, Amsterdam, (1988).

(12) J.A. Gardella Jr. and J.J. Pireaux, Anal. Chem., 62, (1990) 645A-661A.

(13) S. Hofmann, Surf. Interface Anal., 9, (1986) 3-20.

(14) L.C. Feldman and J.W. Mayer, "Fundamentals of Surface and Thin Film Analysis," North-Holland, New York, (1986).

(15) P.F. Kane and G.B. Larrabee, "Characterization of Solid Surfaces," Plenum Press, New York, (1974). 
(16) R.S. Yih and B.D. Ratner, J.Elect. Spectrosc. Rel. Phenom., 43, (1987) 61-82.

(17) B.J. Tyler, D.G. Castner, and B.D. Ratner, Surf. Interface Anal., 14, (1989) 443-450.

(18) S. Kaplan and A. Dilks, J. Polym Sci., Polym. Chem. Ed., 21, (1983) 1819-1829.

(19) I. Sugimoto, Macromolecules, 24, (1991) 1480-1486.

(20) N. Morosoff, B. Crist, M. Bumgarner, T. Hsu, and H. Yasuda, J.Macromol. Sci., Chem., 10, (1976) 451-471.

(21) H.J. Griesser and R.C. Chatelier, J. Appl. Polym. Sci. Appl. Polym. Symp., 46, (1990) 361-384.

(22) D.G. Castner and B.D. Ratner, Trans. Soc. Biomat.erials, 14, (1991) 279.

(23) A. Chilkoti, G.P. Lopez, B.D. Ratner, M.J. Hearn, and D. Briggs, Macromolecules, 26, (1993) 4825-4832.

(24) A. Chilkoti, B.D. Ratner, and D. Briggs, Surf. Interface Anal., 18, (1992) 604-618.

(25) A. Chilkoti, B.D. Ratner, and D. Briggs, Anal. Chem., 65, (1993) 1736-1745.

(26) G.P. Lopez, B.D. Ratner, C.D. Tidwell, C.L. Haycox, R.J. Rapoza, and T.A. Horbett, J. Biomed. Mater. Res., 26, (1992) 415-439.

(27) G.P. Lopez and B.D. Ratner, J. Polym. Sci., Polym. Chem. Ed., 30,(1992) 2415-2425 .

(28) G.J. Leggett, B.D. Ratner, and J.C. Vickerman, Surf. Interface Anal., 23,(1995) 22-28 .

(29) C.R. Savage, R.B. Timmons, and J.W. Lin, Chem. Mater., 3, (1991) 575-577.

(30) D.G. Castner, K.B. Lewis, D.A. Fischer, B.D. Ratner, and J.L. Gland, Langmuir, 9, (1993) 537-542.

(31) H. Yasuda and M. Gazicki, Biomaterials, 3, (1982) 68-77.

(32) B.D. Ratner, A.B. Johnston, and T.J. Lenk,J. Biomed. Mater. Res: Appl. Biomat., 21, (1987) 59-90.

(33) B.D. Ratner, "Correlation, surface chemistry and biomaterials science" in Biomaterials Science: An Introduction, B.D. Ratner, F. Schoen, J. Lemons, and A.S. Hoffman, Eds., Academic Press, San Diego, (1996) in press

(34) A.M. Garfinkle, A.S. Hoffman, B.D. Ratner, L.O. Reynolds, and S.R. Hanson, Trans. Am. Soc. Artif. Int. Organs, 30, (1984) 432-439.

(35) A.S. Hoffman, B.D. Ratner, A.M. Garfinkle, L.O. Reynolds, T.A. Horbett, and S.R. Hanson, in Polymers in Medicine II - Biomedical and Pharmaceutical Applications, E. Chiellini, P. Giusti, C. Migliaresi, and L. Nicolais, Eds., Plenum Press, New York, (1985), pp. 157-173.

(36) J.A. Chinn, T.A. Horbett, B.D. Ratner, M.B. Schway, Y. Haque, and S.D. Hauschka, J. Coll. Interf. Sci., 127, (1989) 67-87.

(37) S.I. Ertel, B.D. Ratner, and T.A. Horbett, J. Biomed. Mater. Res., 24,(1990) 16371659. 
(38) S.I. Ertel, A. Chilkoti, T.A. Horbett, and B.D. Ratner, J. Biomater. Sci. Polymer. Edn., 3, (1991) 163-183.

(39) S.I. Ertel, B.D. Ratner, and T.A. Horbett, J. Coll. Interf. Sci., 147, (1991) 433-442.

(40) A. Chilkoti, A.E. Schmierer, V.H. Perez-Luna, and B.D. Ratner,Anal. Chem., (1995), in press

(41) M. Amiji and K. Park, Biomaterials, 13, (1992) 682-692.

(42) K. Bergstrom, E. Osterberg, K. Holmberg, A.S. Hoffman, T.P. Schuman, A. Kozlowski, and J.M. Harris, J. Biomater. Sci. Polymer. Edn., 6, (1994) 123-132.

(43) N.B. Mateo and B.D. Ratner, Invest. Ophthalom. Vis. Sci., 30, (1989) 853-860.

(44) J. Amouroux, A. Gicquel, S. Cavvadias, D. Morvan, and F. Arefi, Pure \& Appl. Chem., 57, (1985) 1207-1222.

(45) F. Kokai, T. Kubota, M. Ichjyo, and K. Wakai, J. Appl. Polym. Sci. Appl. Polym. Symp., 42, (1988) 197-219.

(46) J. Leu and K.F. Jensen, J. Vac. Sci. Technol. A9, (1991) 2948-2962.

(47) A. Chilkoti, B.D. Ratner, and D. Briggs, Chem. Mater., 3, (1991) 51-61.

(48) A. Chilkoti, B.D. Ratner, and D. Briggs, Anal. Chem., 63, (1991) 1612-1620. 